JURNAL SISFOTENIKA

Vol. 10 No. 1, Januari 2020

p-ISSN: 2087-7897; e-ISSN : 2460-5344

DOI : $10.30700 /$ jst.v10i1.773

\title{
Implementasi Load Balancing Web Server Menggunakan Apache di Ubuntu 16.04.
}

\author{
Implementation Load Balancing Web Server Using \\ Apache on Ubuntu 16.04.
}

\author{
Kresno Wibowo*1, Iskandar Fitri ${ }^{2}$, Deny Hidayatullah ${ }^{3}$ \\ ${ }^{1,2,3}$ Universitas Nasional; Jl. Sawo Manila, RT.14/RW.3, Ps. Minggu, Kec. Ps. Minggu, Kota \\ Jakarta Selatan, Daerah Khusus Ibukota Jakarta 12520, (021) 7806700 \\ e-mail: *11kresnowibow04598@gmail.com, ${ }^{2}$ tektel2001@yahoo.com, ${ }^{3}$ faradeari@ gmail.com
}

\begin{abstract}
Abstrak
Saat banyak pengguna yang mengakses suatu situs web pada saat yang bersamaan. Maka saat itu bisa membuat web server menampung beban yang berlebih karena tidak bisa menampung lagi banyaknya request yang diterima. Dan itu biasa terjadi saat web server tunggal atau single. Namun dengan menggunakan metode load balancing Round Robin dan juga Haproxy sebagai load balancer dapat membantu mengatur pembagian beban pada setiap server. Dengan pegujian yang dilakukan pada 250 user, 500 user, 750 user, sampai 1000 user dan menggunakan web statis. Hingga dapat melihat penggunaan CPU yang digunakan dengan beban user yang diuji pada saat setelah melakukan. Hasil dari pengujian dengan menggunakan haproxy berjalan dengan baik daripada single server dan dua server. Dengan menggunakan apache benchmark dalam menghitung Throughput dan Time per request antara single server, dua server serta menjalankan semua server menggunakan Haproxy. Untuk pengujian presentasi pada CPU yang dipakai pada 250 user yaitu 31,9\% yang terendah namun terdapat peningkatan pada pengujian 1000 user yaitu mencapai 54,5\%. Hasil pengujian pada Dua server dalam pengujian 250 user, 500 user, 750 user, dan 1000 user menghasilkan hasil 62.5\%-68.7\%. Dan dengan pengujian pada single server pemakaian RAM dalam pengujian 250 user, 500 user, 750 user, serta 1000 user yaitu mencapai sekitar 91\%-96\%. Dengan hasil pengujian yang lebih baik menggunakan load balancing haproxy daripada menggunakan single server maupun dua server. Karena penggunaan single server dan dua server hampir mencapai overload. Yang berarti waktu yang dibutuhkan untuk menangani beban tersebut ialah load balancing menggunakan haproxy lebih baik daripada single server untuk lebih cepat menangani request, time per second dan penggunaan $C P U$.
\end{abstract}

Kata kunci - Apache, Haproxy, Load Balancing, Virtual Box

\begin{abstract}
When many users access a website at the same time. So when it can make the web server to accommodate excessive loads because it can no longer accommodate the number of requests received. And that usually happens when a single web server or single. However, using the Round Robin load balancing method and also Haproxy as a load balancer can help regulate load sharing on each server. With testing done on 250 users, 500 users, 750 users, up to 1000 users and using a static web. So you can see the CPU usage that is used by the user load that is
\end{abstract}


tested at the time after performing. The results of testing using haproxy run better than a single server and two servers. By using Apache benchmark in calculating Throughput and Time per request between a single server, two servers and running all servers using Haproxy. For testing the presentation on the CPU that is used on 250 users is $31.9 \%$ the lowest but there is an increase in testing 1000 users, reaching $54.5 \%$. The test results on two servers in testing 250 users, 500 users, 750 users, and 1000 users produced $62.5 \%-68.7 \%$ results. And by testing on a single server RAM usage in testing 250 users, 500 users, 750 users, and 1000 users which reached about $91 \%-96 \%$. With better test results using haproxy load balancing than using a single server or two servers. Because the use of a single server and two servers almost reached overload. Which means the time needed to handle the load is load balancing using haproxy better than a single server to more quickly handle requests, time per second and CPU usage.

Keywords - Apache, Haproxy, Load Balancing, Virtual Box

\section{PENDAHULUAN}

Pada zaman sekarang yang sudah semakin maju era teknologi khususnya pada kemajuan bidang jaringan. Perkembangan tersebut terbilang cukup pesat setiap waktu. Meningkatnya kebutuhan akan informasi menuntut akses yang cepat untuk mendapatkan informasi - informasi terkini, salah satunya yang paling dominan mempengaruhi kecepatan akses suatu alamat website tertentu adalah server penyedia layanan. Server bisa dibilang sebagai pelayan karna tugasnya menerima request dari klien, permintaan datang dari klien yang sudah terhubung pada server yang ingin diakses, server merupakan pusat pengelolaan, semakin banyak klien semakin berat kerja yang dilakukan oleh server, sehingga dibutuhkan spesifikasi komputer khususnya server harus baik sehingga mampu melayani permintaan klien yang cukup banyak. Penelitian sebelumnya yang mengggunakan dua server untuk melakukan load balancing menggunakan nbl manager dilakukan oleh penulis pertama, dkk. Kemudian penelitian yang selanjutnya juga menggunakan metode nth yang dilakukan oleh penulis pertama, dkk [1].

Permasalahan pada umumnya tidak jarang pengelola server kurang mengelola dengan baik web server. Oleh sebab itu sering terjadi server down dan overload akibat banyaknya user yang mengakses secara bersamaan. Karena menggunakan satu server untuk menampung banyaknya permintaan. Karena menggunakan single server tidak ada server lain yang bisa membantu saat terjadi overload [2].

Load Balancing adalah suatu teknik untuk membagi beban pada koneksi secara seimbang, agar koneksi dapat berjalan lancar dan optimal, memaksimalkan throughput, memperkecil untuk terjadinya overload pada salah satu jalur koneksi Load balancing juga membagi beban kerja yang dilakukan secara merata di dua atau lebih komputer, link jaringan, $\mathrm{CPU}$, hard drive, atau sumber daya lainnya, untuk mendapatkan pemanfaatan sumber daya yang optimal. dalam hal ini masalah pada pemerataan beban server menjadi salah satu solusi untuk dapat menjawab permasalahan yang ada diatas[3].

Penelitian ini bertujuan mengimplementasikan load balancing pada web server untuk menjamin kestabilan server dengan cara manajemen yang baik. Maanfaatnya Dapat memperkecil untuk terjadinya overload pada webserver. Dan dengan menggunakan load balancing dengan Algoritma Round Robin yang dapat membagi kinerja web server dengan merata. Karena dapat menjaga kestabilan server karena menggunakan lebih dari satu server.

\section{METODE PENELITIAN}

Perancangan yang akan dibuat ialah membangun sebuah web server yang akan nantinya dijadikan load balancer yaitu haproxy. Metode yang diterapkan dalam penelitian ini menggunakan Load balancing dengan Algoritma Round Robin. Haproxy akan mengambil source dengan beban yang setara antara satu server dengan server lainnya. 
Apache adalah sebuah perangkat lunak web server yang menghubungkan antara web dengan user. Apache memudahkan pemilik website untuk membuat konten. Apache juga merupakan software lintas platform dan server nya dapat berjalan dengan baik.

Round Robin ialah sebuah Algoritma yang dipakai untuk mengambil sourch dengan beban yang setara antara server satu dengan server yang lainnya. Pembagian beban tersebut bertujuan agar saat banyak beban yang masuk secara bersamaan, kinerja server tidak down dan dapat berjalan dengan baik menerima beban.

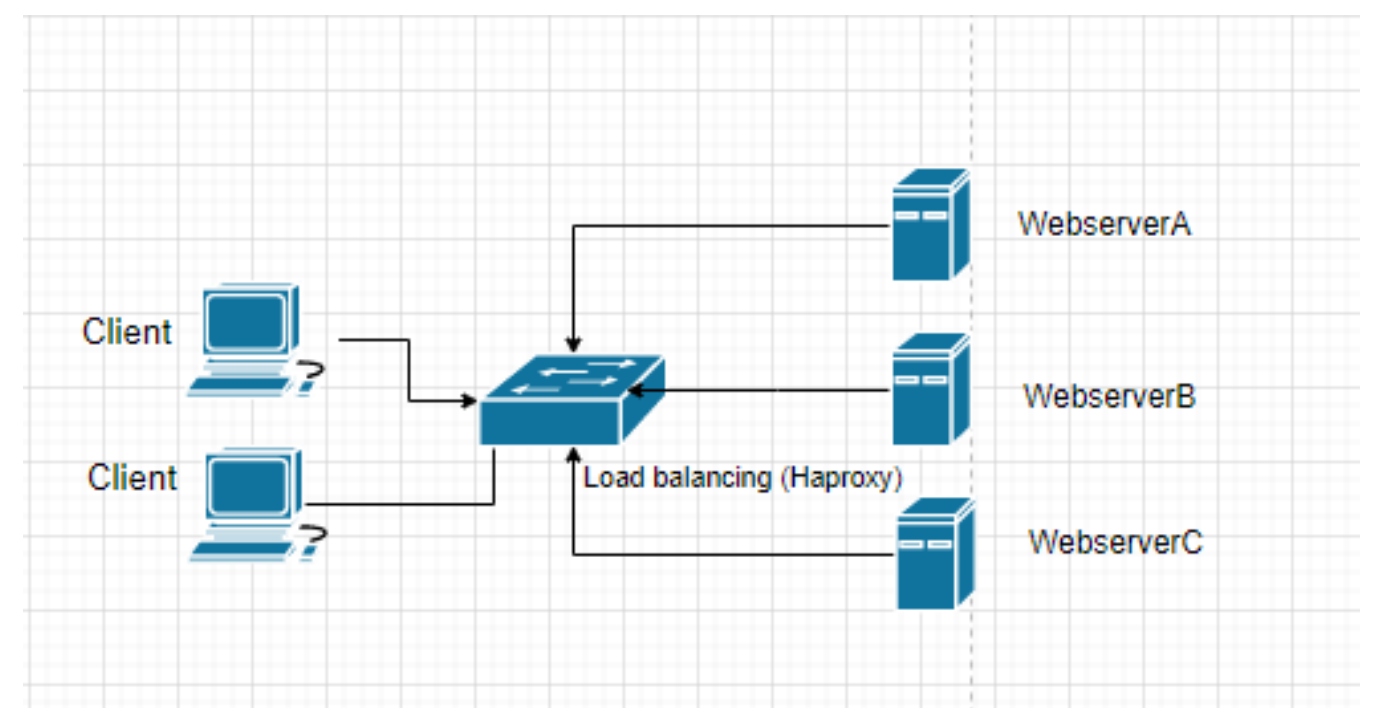

Gambar 1. Topologi yang digunakan

Pada Gambar 1 menunjukkan jalan yang akan dilakukan pada sistem load blancing menggunakan 3 server dengan OS ubuntu 16.04 yang masing-masing sudah diberi web statis. Lalu sebagai load balancing nya menggunakan Haproxy dengan OS ubuntu 16.04 yang nantinya tersambung dengan client.

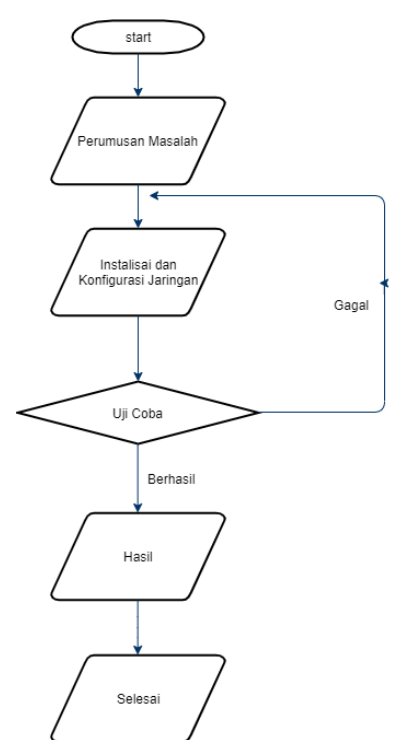

Gambar 2. Tahapan penilitan 
Pada gambar 2 merupakan tahapan penelitian yang dilakukan mulai dari perumusan masalah lalu lanjut terhadap instalisasi yang dilakukan seperti install Ubuntu 16.04 lalu Apache sebagai web server dan Haproxy sebagai Load Balancer. Setelah itu melakukan konfigurasi terhadap tiga server yang diuji dengan haproxy. Lalu lakukan pengujian namun jika pengujian gagal kita kembali melakukan konfigurasi. Sampai pada jika uji coba yang dilakukan berhasil masuk kepada tahap hasil yang diuji lalu selesai.

\section{HASIL DAN PEMBAHASAN}

\section{A. Analisis Kebutuhan}

Pada proses pembuatan aplikasi absensi dalam penelitian ini dibutuhkan beberapa perangkat pendukung seperti perangkat lunak (software) dan perangkat keras (hardware), yang diantaranya:

1. Kebutuhan Hardware : Laptop Intel Core i3-6006U, 2.0GHz dengan RAM 8GB dan HDD 1TB

2. Kebutuhan Software : Virtualbox, Google Chrome, Draw.io, Ms. Excel.

B. Tampilan Aplikasi

Pada proses ini tampilan web server dengan ip address yang digunakan untuk melakukan Load Balancing. WebserverA dengan Ip Address 192.168.43.10 sebagai server yaitu Apache. WebserverB dengan Ip Address 192.168.43.11 juga sebagai server yaitu Apache. WebserverD dengan Ip Address 192.168.43.13 juga sebagai server yaitu Apache. Lalu ada sebagai load balancer yaitu webserverL dengan Ip Adress 192.168.43.25 dengan load balancer Haproxy yang digunakan.

Tabel 1. IP Adress

\begin{tabular}{ccc}
\hline Nama & Ip Address & Isi \\
\hline webserverA & 192.168 .43 .10 & Apache \\
\hline webserverB & 192.168 .43 .11 & Apache \\
\hline webserverD & 192.168 .43 .13 & Apache \\
\hline webserverL & 192.168 .43 .25 & Haproxy \\
\hline
\end{tabular}

Haproxy Stats ialah hasil yang akan ditampilkan saat sudah melakukan load balancing web server. Untuk mengetahui hasil tersebut maka terlebih dahulu melakukan testing terhadap load balancer.

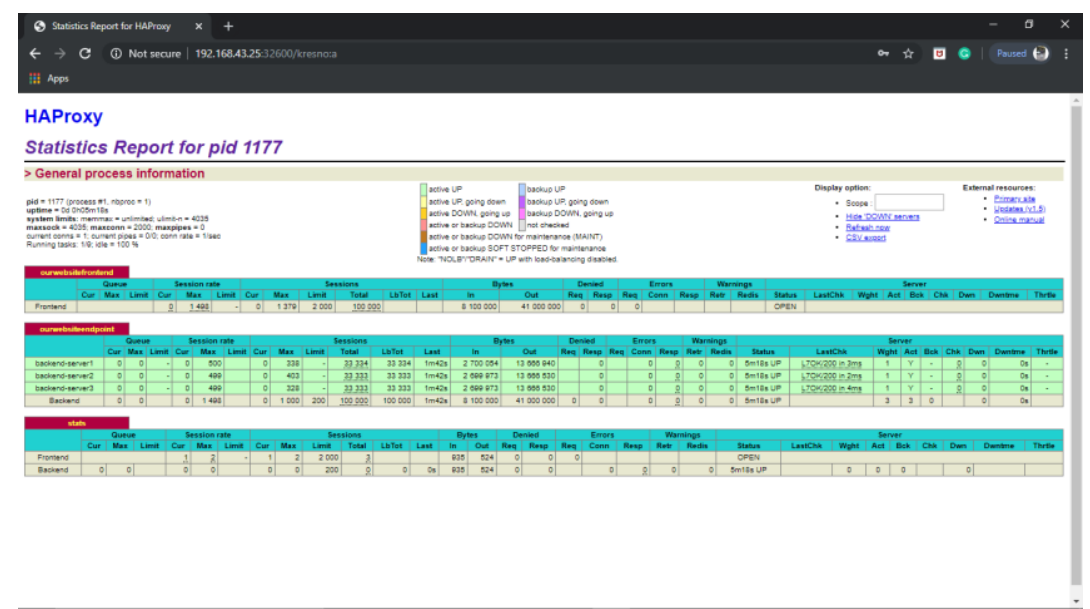

Gambar 2. Statistik tampilan Haproxy 
Gambar 2 Berikut adalah hasil yang ditampilkan dari hasil static yang nanti tiga web server tersebut akan dilakukan load balancing dengan memasukkan data yang akan diuji dengan diberi beban yang ingin diuji.

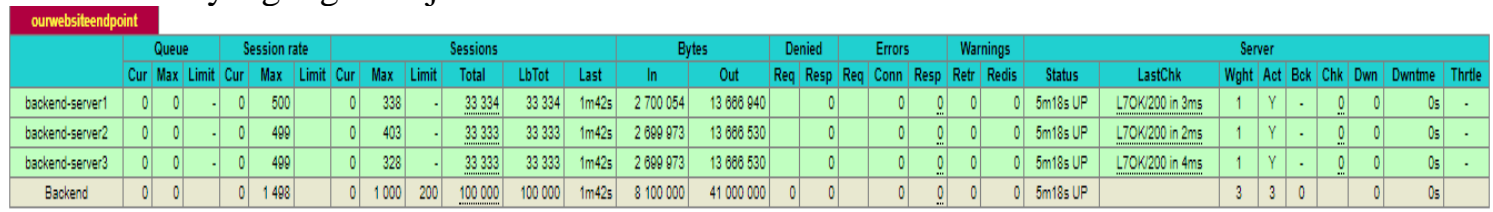

Gambar 3. Hasil yang ditampilkan

Pada Gambar 3. Seperti yang dilihat pada gambar 3 ialah tampilan lebih jelas yang akan keluar setelah melakukan load balancing dengan menggunakan load balancer haproxy yaitu dapat menampilkan tiga server hasil dari pengujian.

C. Pengujian

Dalam proses pengujian yang akan dilakukan pada penelitian ini ialah memasukkan dari 250, 500, 750 sampai 1000 permintaan akses user. Pengujian tersebut meliputi hasil pengujian request persecond, transfer rate, dan penggunaan memory.

\begin{tabular}{|c|}
\hline $\begin{array}{l}\text { frontend ourwebsitefrontend } \\
\text { bind } *: 80 \\
\text { mode http } \\
\text { default_backend ourwebsiteendpoint } \\
\text { backend ourwebsiteendpoint } \\
\text { balance roundrobin } \\
\text { option forwardfor } \\
\text { http-request set-header X-Forwarded-Port [dst_port] } \\
\text { http-request set-header X-Forwarded-Proto https if \{ssl_fc \} } \\
\text { option httpchk HEAD / HTTP/1.1\r\Host:localhost } \\
\text { server backend-server1 } 192.168 .43 .11: 8080 \text { check } \\
\text { server backend-server2 } 192.168 .43 .10: 8080 \text { check } \\
\text { server backend-server3 } 192.168 .43 .25: 8080 \text { check } \\
\text { listen stats } \\
\text { bind : } 32600 \\
\text { stats enable } \\
\text { stats uri / } \\
\text { stats hide-version } \\
\text { stats auth kresno:a }\end{array}$ \\
\hline
\end{tabular}

\section{Gambar 4. Konfigurasi Haproxy}

Pada gambar 4. Terlihat pada gambar 4 yaitu saat melakukan konfigurasi untuk menghubungkung antara web server 1 , web server 2 , web server 3 dengan load balancer. Untuk melakukan load balancing, agar masuk ke konfigurasi pada Gambar 4 nano letc/haproxy/haproxy.cfg, harus memasukkan ip address web server yang akan digunakan seperti Gambar 4 untuk web server 1 -192.168.43.10, web server 2 -192.168.43.11 web server 3 -192.168.43.13 dan untuk haproxy sendiri memiliki ip address yaitu web serverL 192.168.43.25.

\section{rootQubuntu:/home/kresnoł ab -n 10000 -c 1000 http://192.168.43.25/}

Gambar 5. Apache benchmark

Pada gambar 5, terlihat pada gambar 5 ialah Untuk pengujian menggunakan Apache Benchmark memasukkan script seperti Gambar 5. Parameter c adalah untuk menguji jumlah request yang ingin diuji, sedangkan parameter $\mathrm{n}$ adalah jumlah koneksi yang nantinya dibuat untuk ke server tujuan, lalu masukkan ip addres tujuan yang ingin diuji yaitu load balancer nya. 


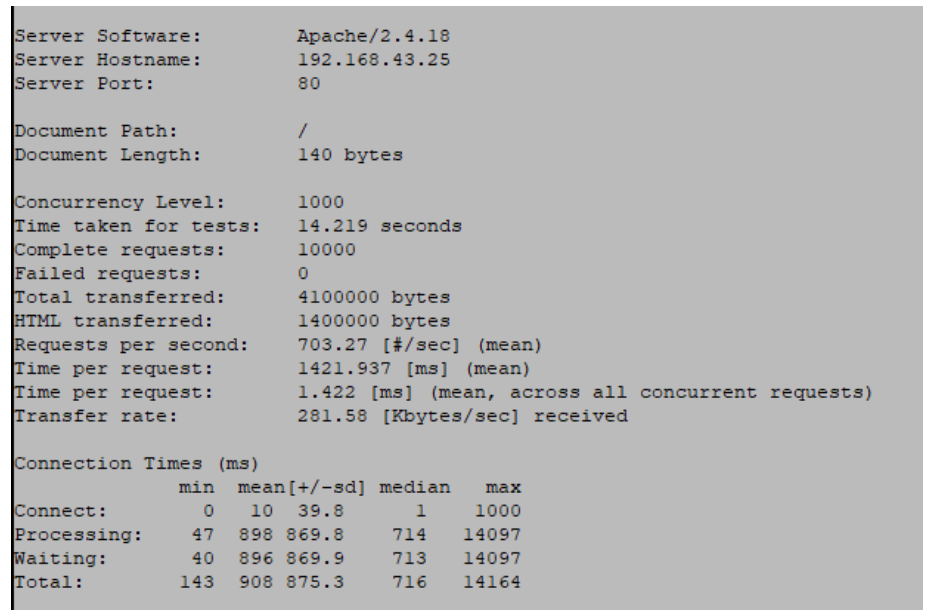

\section{Gambar 6. Hasil Apache benchmark}

Pada gamber 6, terlihat dari hasil pengujian dengan 1000 user ialah untuk hasil dari time per request menghasilkan angka 1.033, dan untuk transfer rate yaitu dengan hasil 387.49 (kbytes/sec),begitu juga dengan hasil dari time takes for tests menghasilkan 10.333 second, dan juga hasil dari request per second yaitu mencapai 967.77 (/sec).

Tabel 2. Pengujian kinerja RAM

\begin{tabular}{cccc}
\hline Jumlah User & Nama Server & \%of CPU & Memory \\
\hline 250 & webserverA & $31,9 \%$ & 227 \\
\hline & webserverB & $33,6 \%$ & 225 \\
\hline & webserverD & $34,3 \%$ & 226 \\
\hline 500 & webserverA & $42,6 \%$ & 220 \\
\hline & webserverB & $42,3 \%$ & 256 \\
\hline & webserverD & $47,2 \%$ & 252 \\
\hline 750 & webserverA & $39,1 \%$ & 275 \\
\hline & webserverB & $43,5 \%$ & 274 \\
\hline & webserverD & $49,3 \%$ & 273 \\
\hline & webserverA & $38,7 \%$ & 256 \\
\hline & webserverB & $45,8 \%$ & 274 \\
\hline & webserverD & $54,4 \%$ & 277 \\
\hline
\end{tabular}

Pada Tabel 2 adalah hasil penggunaan RAM dengan menggunakan htop setelah melakukan pengujian. Dari hasil pengujian \% of RAM yang telah diringkas menjadi tabel agar mudah membacanya. Pembagian pada beban 3 web server ubuntu yang tersedia menggunakan Haproxy sebagai load balancer secara fungsional. Pada pengujian 250 user untuk pembagian beban yang hampir setara yaitu dengan hasil diangka 31-34\%. Di 500 user juga hasil pembagian hampir setara yaitu dihasil 42-47\%. Di 750 user mulai terjadi perbedaan karena web serverA menghasilkan 39,1\% sementara web serverB 43,5\% dan web serverD menghasilkan 49,3\%. Dari web serverA dan D memiliki selesih 10\%. Di 1000 user web serverA.

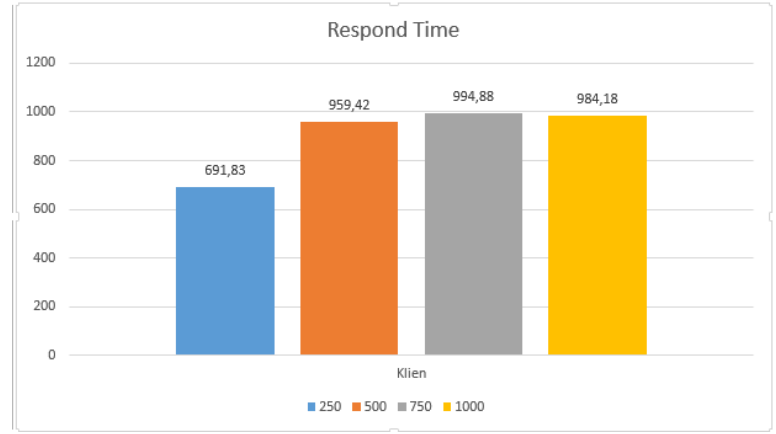




\section{Gambar 6. Respond Time}

Pada gambar 6, terlihat gambar 6 menunjukkan hasil dari saat melakukan Apache Bencmark untuk request per second yang pada pengujian 250 user yang berada pada angka 691.83 per second. untuk pengujian pada 500 user yaitu menghasilkan pada angka 959.43 per second. Pada pengujian untuk 750 user yaitu mencapai angka 994.88 per second. dan untuk pengujian terakhir yaitu pada 1000 user menghasilkan angka mencapai 984.18 per second.

Tabel 3. Pengujian single server

\begin{tabular}{ccccc}
\hline Nama & User & \%ofCPU & Memori & Request per second \\
\hline Webserver & 250 & $91,9 \%$ & 225 & 1061.31 \\
\hline Webserver & 500 & $93,4 \%$ & 229 & 1004.27 \\
\hline Webserver & 750 & $95,5 \%$ & 231 & 1060.485 \\
\hline Webserver & 1000 & $96.0 \%$ & 235 & 1313.786 \\
\hline
\end{tabular}

Pada Tabel 3 menujukkan kinerja server yang sangat besar jika menggunakan single server. Karena tidak ada yang bisa membatu saat banyak user mengakses dengan jumlah besar. Oleh karena itu akhirnya sudah hampir memenuhi kapasitas dan terjadi overload. Terlihat penggunaan yang digunakan pada pengujian 250 user yaitu mencapai angka 91,9\%, dan pengujian 500 user juga mencapai hasil 93,4\%, sementara untuk pengujian 750 user mencapai angka 95,5\%, dan untuk pengujian 1000 user yaitu mencapai angka tertinggi yaitu 96,0\%. Ini adalah hasil jika penggunaan single server saat melalukan menerima beban yang cukup besar. Angka yang dihasilkan cukup tinggi dikarenakan server hanya bekerja sendiri tanpa ada pembagian beban ke server lainnya.

Tablel 4. Pengujian dua server

\begin{tabular}{ccccc}
\hline User & Nama & \%ofCPU & Memori & Request per Second \\
\hline 250 & webserverA & $65,3 \%$ & 223 & 1134.44 \\
\hline & webserverB & $67.8 \%$ & 225 & 1087.50 \\
\hline 500 & webserverA & $63.4 \%$ & 231 & 1091.93 \\
\hline & webserverB & $66.2 \%$ & 236 & 1023.30 \\
\hline 750 & webserverA & $67,8 \%$ & 232 & \\
\hline & webserverB & $68.4 \%$ & 229 & \\
\hline
\end{tabular}

Pada tabel 4. Terlihat pengujian menggunakan dua server atau satu server yang dimatikan terlihat bahwa penggunaan RAM cukup meningkat jika tidak menggunakan semua server. Yaitu dengan hasil pengujian dari 250 user untuk webserverA mencapai $65,3 \%$ sementara untuk webserverB mencapai $67,8 \%$. Untuk hasil pengujian dari 500 user untuk webserverA sendiri mencapai $63,4 \%$ sementara untuk webserverB mencapai 66,2\%. Dan untuk hasil dari pengujian dari 750 user juga untuk webserverA mencapai $67,8 \%$ sedangkan untuk webserverB menghasilkan 68,4\%. Dan untuk pengujian terakhir yaitu 1000 user untuk webserverA mencapai $68,7 \%$ dan hasil lebih rendah yaitu webserverB dengan hasil $62,5 \%$. Meskipun menggunakan dua server tetap penggunaannya masih diatas 50\% atau setengah lebih dari kapasitas seharusnya. 
Tabel 5. Pengujian hasil load balancing

\begin{tabular}{lllll}
\hline User & $\begin{array}{l}\text { Time taken for test } \\
{[\text { second] }}\end{array}$ & $\begin{array}{l}\text { Request per second } \\
{[\# / \mathrm{sec}]}\end{array}$ & $\begin{array}{l}\text { Time per request } \\
{[\mathrm{ms}]}\end{array}$ & Transfer rate [kbytes/sec] \\
\hline 250 & 9.029 & 1083.40 & 0.923 & 433.78 \\
\hline 500 & 9.060 & 1103.80 & 0.906 & 441.95 \\
\hline 750 & 9.244 & 1081.76 & 0.924 & 433.13 \\
\hline 1000 & 9.284 & 1077.16 & 0.928 & 431.28 \\
\hline
\end{tabular}

Pada tabel 5 Menampilkan hasil dari time taken for test, request per second, time per request, dan juga transfer rate. Karena menggunakan Algoritma Round Robin maka bisa dilihat pembagian yang merata pada pengujian load balancing. Hasil pengujian pada tabel 5 dari time taken for test untuk pengujian 250 user ialah 9.029, 500 user ialah 9.060, 750 user ialah 9.244, dan untuk 1000 user mencapai 9.284. Dan hasil request per second dari 250 user ialah 1083.40/sec, 500 user mencapai 1103.80/sec, dan 750 user dengan hasil 1081.76/sec, dan untuk 1000 user mencapai 1077.16. untuk time per request hasil dari 250 user ialah $0.923,500$ user mencapai 0.906, 750 user mencapai angka 0.924, lalu untuk 1000 user mencapai angka 0.928. dan untuk hasil dari transfer rate dari hasil 250 user mencapai 433.78, untuk 500 user mencapai 441.95, dan 750 user mencapai 433.13, dan yang terakhir untuk 1000 user mencapai 431.28. Hasil tersebut cukup stabil saat melakukan load balancing karena pembagian yang cukup merata.

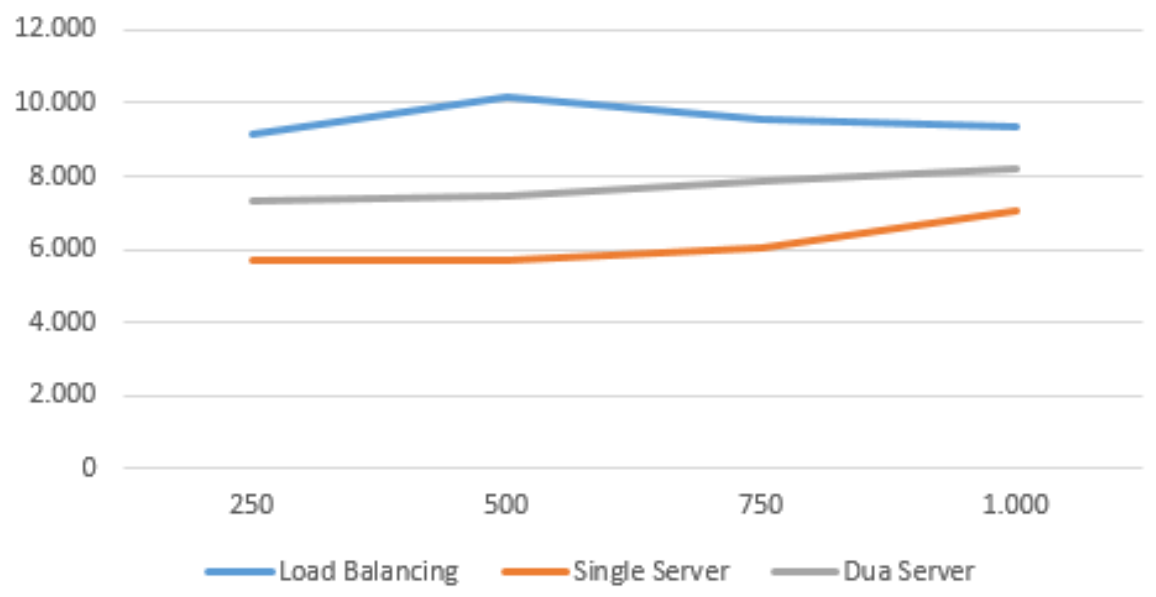

Gambar 7. Perbandingan Single Server dengan Load Balancing

Berdasarkan pada pengujian gambar 7 , data yang telah dihasilkan dari waktu respon ialah diketahui dari 500 client, single server dapat melayani dengan baik setiap data yang masuk. Namun ketika diatas 500 client maka kinerja nya mulai berkurang akibat banyaknya data yang masuk. Begitupun dengan dua server tidak berbeda jauh dengan single server, karena pembagian bebannya hanya ke satu server tersisa walaupun tetap bisa membagi beban namun dapat berjalan dengan baik. Namun tidak dengan menggunakan load balancing karena ada pembagian beban yang dilakukan saat melayani jumlah user yang meningkat. 


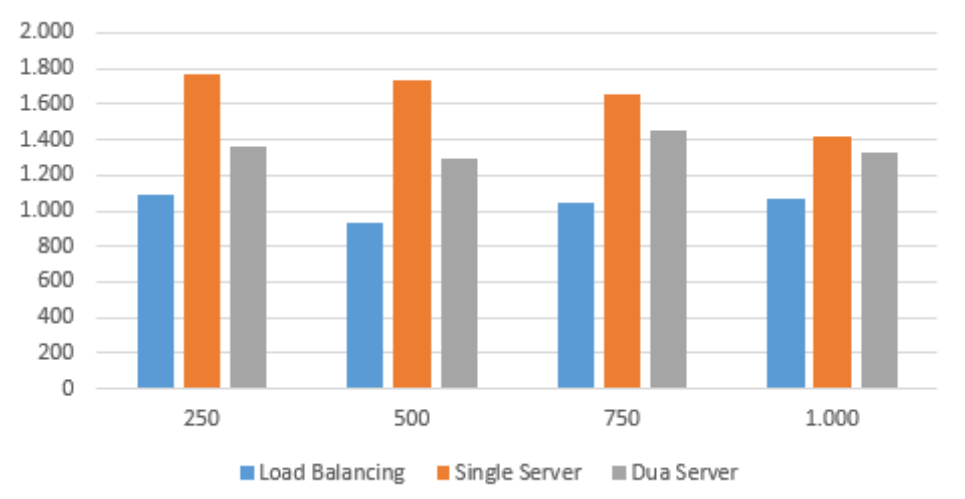

Gambar 8. Perbandingan request

Pada gambar 8 hasil dari pengujian request. Terlihat bahwa menggunakan load balancing sangat berjalan dengan baik dibandingkan dengan single server maupun dua server. Dengan menggunakan single server terlihat setiap request yang masuk maka sudah akan terjadinya overload dari server tersebut karena server hanya bekerja sendiri disaat masuknya request. Seperti halnya single server, dua server juga tidak berbeda jauh meskipun ada satu server lagi yang membantu disaat masuknya request. Dan menggunakan load balancing tiga server baru mulai dapat membagi beban dengan stabil dan berjalan cukup baik.

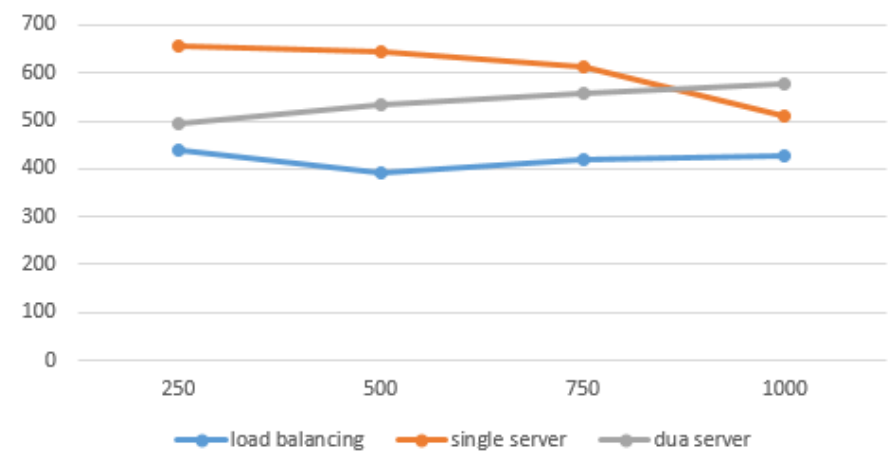

Gambar 9. Perbandingan Transfer Rate

Pada pengujian gambar 9. Transfer Rate yang menggunakan load balancing lebih stabil dan lebih kecil dibandingkan dengan single server yang cukup tinggi dan perbedaannya cukup terlihat. Sedangkan dua server berada diantara single server dan load balancing. Pada load balancing berada diangka 393.83-438.87[kbytes/sec]. dan untuk dua server 496.73$578.65[\mathrm{kbytes} / \mathrm{sec}]$. sedangkan untuk pengujian single server yaitu 512.03-656.49[kbytes/sec].

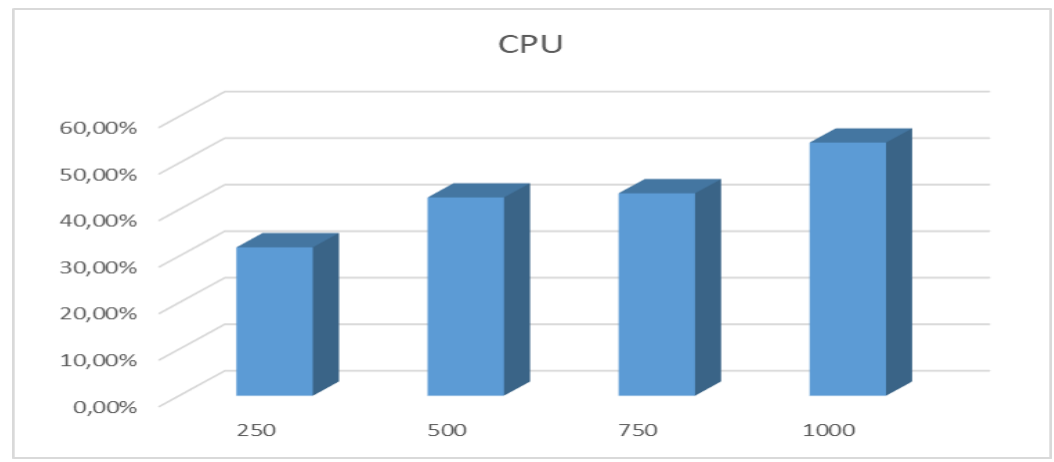


Gambar 10. Penggunaan Memori load balancing

Pada pengujian gambar 10. Penggunaan Memori pada pengujian load balancing terlihat lebih stabil dan tidak terlalu berbeda jauh. Oleh karena itu penggunaannya berjalan dengan baik dengan pengujian mulai dari 250 user yaitu 32,9\%, 500 user mencapai $42.6 \%$, pada 750 user berada pada angka $43.5 \%$, dan untuk 1000 user $54.4 \%$. setiap penggunaan yang lebih besar, maka terdapat peningkatan pemakaian memori pada setiap prosesnya.

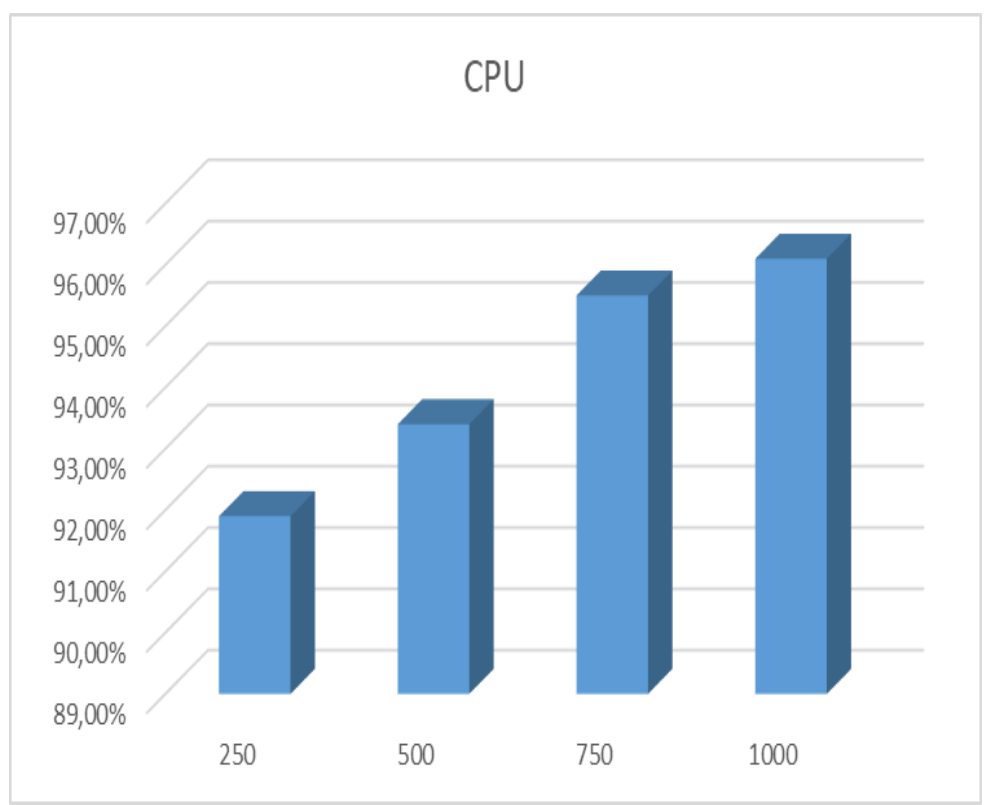

Gambar 11. Penggunaan memori single server

Pada pengujian gambar 11. Pengujian pada single server terlihat pada pengujian tersebut bahwa penggunaan single server tidak berjalan dengan baik karena memiliki kapasitas yang tidak cukup besar. Seperti yang sudah diuji dengan 250 user yaitu berada pada angka 91,9\%, sedangkan 500 user 93,4\%, lalu 750 user mencapai 95.5\%, dan untuk 1000 user mencapai $96.1 \%$. terlihat pada pengujian menggunakan single server kapasitas yang digunakan hampir overload. Karena saat melakukan proses tidak ada yang dapat membantu saat banyaknya data yang masuk. Karena single server bekerja sendiri. Ini membuktikan bahwa single server tidak cukup untuk menampung data yang cukup banyak. 


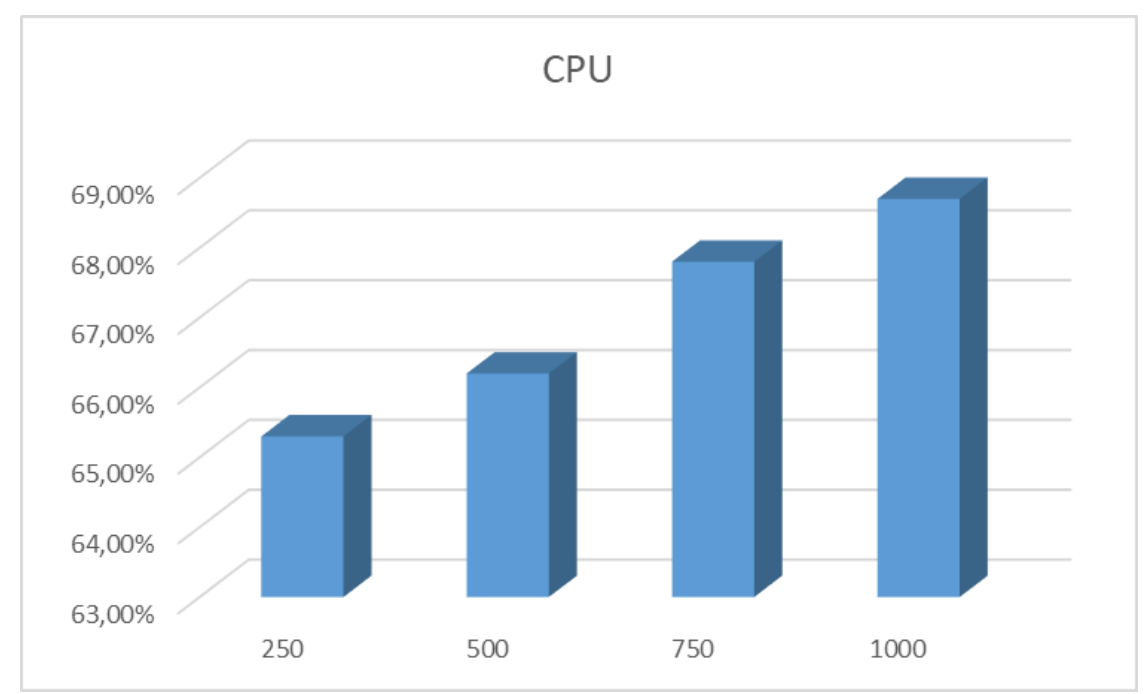

Gambar 12. Penggunaan memori dua server

Pada pengujian gambar 12. Terlihat pengujian pada dua server dapat membagi beban yang ditanggung walaupun masih di angka yang cukup tinggi yaitu masih diatas $50 \%$ yaitu yang berarti melebihi dari setengah kapasitas yang dapat digunakan. Seperti pengujian yang sudah dilakukan dengan pengujian mulai dari 250 user mendapatkan hasil 65,3\%, 500 user mencapai $66,2 \%$, dan 750 mencapai 67,8\%, dan 1000 user mencapai 68,7\%. Terlihat pada pengujian dua server pembagian beban cukup berjalan dengan baik walaupun hanya menggunakan dua server. Karena saat data masuk server tidak bekerja sendirian seperti halnya saat menggunakan single server.

\section{KESIMPULAN}

Dari hasil uji coba dalam pembahasan di atas, maka dapat disimpulkan:

a. Secara fungsi load balancing menggunakan Haproxy berjalan dengan baik. Dengan menggunakan tiga web server dengan Apache.

b. Untuk pengujian presentasi pada CPU yang dipakai pada 250 user yaitu $31,9 \%$ yang terendah namun terdapat peningkatan pada pengujian 1000 user yaitu mencapai 54,5\%. Namun pada titik tertinggi itu load balancing menggunakan Haproxy berjalan dengan baik pada pembagian beban kepada 3 server tersebut. Dan dapat memperlihatkan bila semakin besar beban user yang mengakses, maka semakin besar juga kinerja web untuk bekerja.

c. Untuk hasil pengujian menggunakan single server cukup terlihat beban yang besar terjadi. Terlihat pemakaian RAM dalam pengujian 250, 500, 750, 1000 user yaitu sekitar 91\%-96\% ini bisa terjadi overload karena penggunaan yang hampir $100 \%$ ketika dijalankan. Dan penggunaan dua server berada di sekitar 62.5\%-68.7\% pada hasil dari pengujian.

\section{SARAN}

Dari hasil penelitian yang telah dilakukan dengan menggunakan tiga server dengan satu load balancer cukup berjalan dengan baik. Yang data yang di uji muai dari 250, 500, 750 sampai 1000 user. Dengan hasil pada pengujian CPU yang dipakai pada pengujian 250 user yaitu 31,9\% yang terendah namun mendapatkan peningkatan pada pengujian 1000 user 54,5\%. Namun pada penggunaan single server terlihat kapasitas yang hampir overload karena server hanya bekerja 
sendiri. Pada pengujian dua server cukup baik pembagian beban walaupun penggunaan juga masih diatas 50\%. Namun saat dicoba melebihi 1000 mulai tidak dapat menampung banyaknya data yang diterima. Oleh karena itu disarankan jika ingin menggunakan kapasitas lebih besar disarankan untuk menambah lagi beberapa server agar dapat menampung data yang lebih besar lagi.

\section{DAFTAR PUSTAKA}

[1]. Muhammdad Sholikin, Muhammad Akbar, Zaid Amin "Analisis Performasi Server Cluster Pada Load Balancing Web Server Menggunakan NBL MANAGER".

[2]. Denny Rachmawan, Dadan Irwan, Harum Argyawati, 2016, "Penerapan Teknik Load Balancing pada Web Server lokar dengan metode Nth menggunakan Mikrotik"

[3]. Alam Rahmatulloh, Firmansyah MSN 2017, "Implementasi load balancing web server menggunakan haproxy dan sinkronisasi file pada sistem informasi akademik Universitas Siliwangi”.

[4]. Syaqia Azizah, Asmunin, 2017, "Implementasi Load Balancing web server menggunakan Haproxy”, Jurnal Management Informatika, Vol 8 ,No.01, 2017.

[5]. Efendi Yusuf, Tengku A Riza, Tody Ariefianto, 2013, "Impelemtasi Teknologi Load Balancer denga web server nginx untuk mengatasi beban server", STMIK AMIKOM Yogyakarta, Januari 2013.

[6]. Fajar Zuhroni, Adian Fatchur Rochim, Eko didik Wudianto, "Analisa Performasi Layanan Kluster Server Menggunakan Penyeimbang Beban dan Virtualbox". Jurnal Teknologi dan Sistem Komputer, Vol 3, No.4, Oktober 2015

[7]. Abe Wisnu Syaputra, Setiawan Asseegaff 2017, "Analisis dan Implementasi Load Balancing dengan Metode NTH pada Jaringan Dinas Pendidikan Provinsi Jambi," 2017 JurnalManajemenSistemInformasi Vol.2, No.4, Desember 2017

[8]. Sampurna Dadi Riskiono, 2018, "Implementasi Metode Load Balancing dalam mendukung Sistem Kluster Server".

[9]. Syamsul Alam Haris, Hero Suhartono, Herlawati, 2018, "Menjaga Kestabilan Jaringan Load Balancing Nth dengan teknik Failover Pada PT. Jakarta Samudera Sentosa Jakarta".

[10]. Warman I, Andrian A. 2017. Analisis Kinerja Load Balancing Dua line Koneksi Dengan Metode Nth. Jurnal TEKNOIF 5(1): 56-62

[11]. Futri Utami, Lindawati Lindawati, Suzan Zefi, 2017, "Optimalisasi load balancing dua ISP untuk manajemen bandwidth berbasis Mikrotik". 